\title{
Arterial counterpulsation in severe refractory heart failure complicating acute myocardial infarction
}

\author{
MICHAEL F. O'ROURKE, NEVILLE SAMMEL, AND VICTOR P. CHANG \\ From the School of Medicine, University of New South Wales, and St Vincent's Hospital, \\ Sydney, Australia
}

SUMMARY The role of arterial counterpulsation was sought in 100 patients with severe refractory cardiac failure complicating myocardial infarction. Seventy-four were in shock and 26 were not. Average duration of counterpulsation was 7.0 days. Hospital survival was 34 per cent (25/74) in shock (predicted $<10 \%$ ) and 65 per cent in patients who were not in shock (predicted $<50 \%$ ). Survival at 4 years was $10 \pm 4$ per cent in shock and $37 \pm 11$ per cent in patients not in shock; functional status was class 1 or 2 in 5 of 9 patients in shock and in 8 of 12 survivors not in shock. Results were best when counterpulsation was started early after onset of symptoms, when ischaemic pain was still present, or when a mechanical defect was corrected surgically. Early coronary artery bypass surgery performed alone in 9 patients did not influence survival or functional status. Complications of counterpulsation occurred in 17 patients in shock and in 2 patients not in shock, all but 6 on the first day; none directly caused death. Counterpulsation is an effective and safe adjunct to medical treatment of complicated infarction provided the intervention is prompt.

Ten years after the first application of intra-aortic balloon counterpulsation in man (Kantrowitz et al., 1969) there is still no consensus as to its role in the management of acute myocardial infarction. Physiological principles concerning the left ventricle's demand for and supply of blood (Sarnoff et al., 1958; Berne, 1964) strongly suggest that such a role exists, as do experimental findings in animals with myocardial ischaemia and early infarction (Soroff et al., 1963; Brown et al., 1967; Goldfarb et al., 1968; Powell et al., 1970; Maroko et al., 1972). However, in the 2 clinical syndromes of acute coronary disease with which most experience has been obtained-cardiogenic shock on the one hand and coronary insufficiency on the other-many published results show little benefit over conventional therapy (Scheidt et al., 1973; Forrester et al., 1976; Mundth, 1976). Furthermore, where benefit has been evident, counterpulsation has often been combined with coronary artery bypass surgery so that its own role has remained uncertain (Dunkman et al., 1972; Sanders et al., 1972; Leinbach et al., 1973; Miller et al., 1974; Willerson et al., 1975; Bardet et al., 1977; Erich et al., 1977).

We report here our experience with the first 100

Received for publication 9 May 1978 patients with acute infarction who were treated with counterpulsation over a 5-year period. These patients were accepted from a group of over 300 referred for consideration of mechanical heart assistance (O'Rourke et al., 1975, 1976).

\section{Criteria and procedure}

In the first 8 months of this project (November 1971 to July 1972), we followed strictly the procedure adopted at the Massachusetts General Hospital (Dunkman et al., 1972; Sanders et al., 1972); we reserved counterpulsation for patients who met the strict MIRU criteria of cardiogenic shock (Dunkman et al., 1972) and subjected all patients on counterpulsation to coronary angiography within the first 48 hours with a view to early coronary artery bypass surgery. Results at this stage were dismal (O'Rourke et al., 1975). We attributed these poor results to the unrealistically strict definition of shock, to the delays incurred in preliminary assessment, and to the trauma of cardiac diagnostic and surgical procedures. We, therefore, developed a different procedure which we have followed strictly over the latter part of this project.

Our present procedure requires (1) a diagnosis of definite acute myocardial infarction by WHO 308 
criteria (WHO, 1970), (2) definite evidence of acute severe heart failure by clinical and radiological criteria (WHO, 1970), or (if such signs are equivocal) an increase in pulmonary artery pressure above $16 \mathrm{mmHg}$ wedge or $20 \mathrm{mmHg}$ mean, and (3) absent or completely unsatisfactory response to medical treatment over at least a 2-hour period, such treatment to include oxygen by mask, relief of pain, adequate diuretics (the minimum dose of frusemide was $80 \mathrm{mg}$ by intravenous injection), and correction of haemodynamically significant arrhythmias. The MIRU definition of cardiogenic shock (Dunkman et al., 1972; Sanders et al., 1972; O'Rourke et al., 1975) was modified by (a) foregoing the requirement of pulmonary and systemic catheterisation before counterpulsation if clinical signs of cardiac failure were unequivocal and if indirect pressure in the brachial artery was less than $100 \mathrm{mmHg}$ systolic and (b) allowing urine output up to $25 \mathrm{ml} /$ hour with diuretic therapy. All other aspects of the 'MIRU definition' (Dunkman et al., 1972) were retained.

Our present procedure requires that diagnostic cardiac catheterisation and coronary angiography be performed only if (1) a mechanical complication is suspected, (2) a patient cannot be weaned from counterpulsation after 2 weeks, or (3) angina pectoris recurs after counterpulsation is terminated. The procedure no longer includes consideration of early coronary artery bypass surgery. The procedure requires that counterpulsation be continued until maximal clinical improvement has been attained and maintained for at least 3 days. At this stage (usually after 7 to 10 days), a trial of weaning is performed (O'Rourke et al., 1975). If deterioration occurs, counterpulsation is continued for a further 4 to 7 days and the trial repeated. If no deterioration occurs, the balloon catheter is removed.

Avco catheters and consoles were used throughout. The balloon catheter was inserted through a 'dacron' side graft into the femoral artery (Kantrowitz et al., 1968). Monitoring catheters were placed in the pulmonary and brachial or radial artery of all patients. In the interests of expediency this procedure was usually done at the same time as the surgical team was cannulating the femoral artery. Heparin (usually 5000 international units intravenously, 4 hourly) was administered to all patients except those undergoing cardiac surgery; and these were given low molecular weight dextran $(10 \mathrm{ml} /$ hour $)$ during operation instead. Cephalothin $(0.5 \mathrm{~g}$ intravenously, 6 hourly) was administered routinely. Drug treatment for heart failure was continued but adjusted when improvement occurred.

In this study, contraindications to counterpulsation were similar to those applied by others
(Dunkman et al., 1972; Sanders et al., 1972), and included age $>70$, pre-existing uncontrolled heart failure, severe symptomatic peripheral vascular disease, severe intercurrent disease, and aortic regurgitation.

No patient was lost to follow-up (which was done by personal interview and examination in all but one survivor), 1 to 52 (mean 24) months after discharge.

\section{Patients}

Seventy-four patients were in cardiogenic shock (Table 1) and 26 were not (Table 2). The 74 in shock comprised 58 with myocardial power failure alone and 16 with a mechanical complication which caused or contributed to shock. Fourteen of the 16 mechanical complications were a consequence of myocardial disruption (Table 3). There was only one mechanical complication (ventricular pseudoaneurysm) in the group of patients without shock. Most patients had been transferred from other hospitals, a factor which explained in part the long delay (median 24 hours for patients in shock and 34 hours without) between onset of symptoms and initiation of counterpulsation. Age (mean 55 and 53), incidence of previous infarction (approximately 1 in 3), heart rate (110 and 118 beats $/ \mathrm{min}$ ), and pulmonary artery pressure (mean 34 and $32 \mathrm{mmHg}$ ) were similar in the groups with and without shock.

Predicted survival rate for patients with shock was < 10 per cent (Wan et al., 1971; O'Rourke et al., 1975; O'Rourke, 1977) and for patients without shock was < 50 per cent from Peel et al. (1962) and Norris et al. (1969) indices (Table 2). Of the first 200 patients referred to us for consideration of counterpulsation, 39 met the criteria but did not proceed to counterpulsation. Of these, only $2(5 \%)$ (including 1 patient who was not in shock) were hospital survivors.

\section{Results}

(a) PATIENTS IN CARDIOGENIC SHOCK

Initiation of counterpulsation was associated with clinical improvement in the majority of patients. Relief was manifest in reduction of mean pulmonary artery pressure and heart rate from $34 \pm 10 \mathrm{mmHg}$ and $110 \pm 22 / \mathrm{min}$ to $26 \pm 10 \mathrm{mmHg}$ and $98 \pm$ $17 / \mathrm{min}$, respectively, by the end of the first day $(P<0.001$ for each by paired $t$ test $)$. Deterioration during counterpulsation was seen only in patients who remained in shock or acute renal failure despite counterpulsation and in those undergoing early trials of weaning, angiography, and cardiac surgery. Deterioration after termination of counterpulsation was, however, common. 
Table 1 Patients with cardiogenic shock

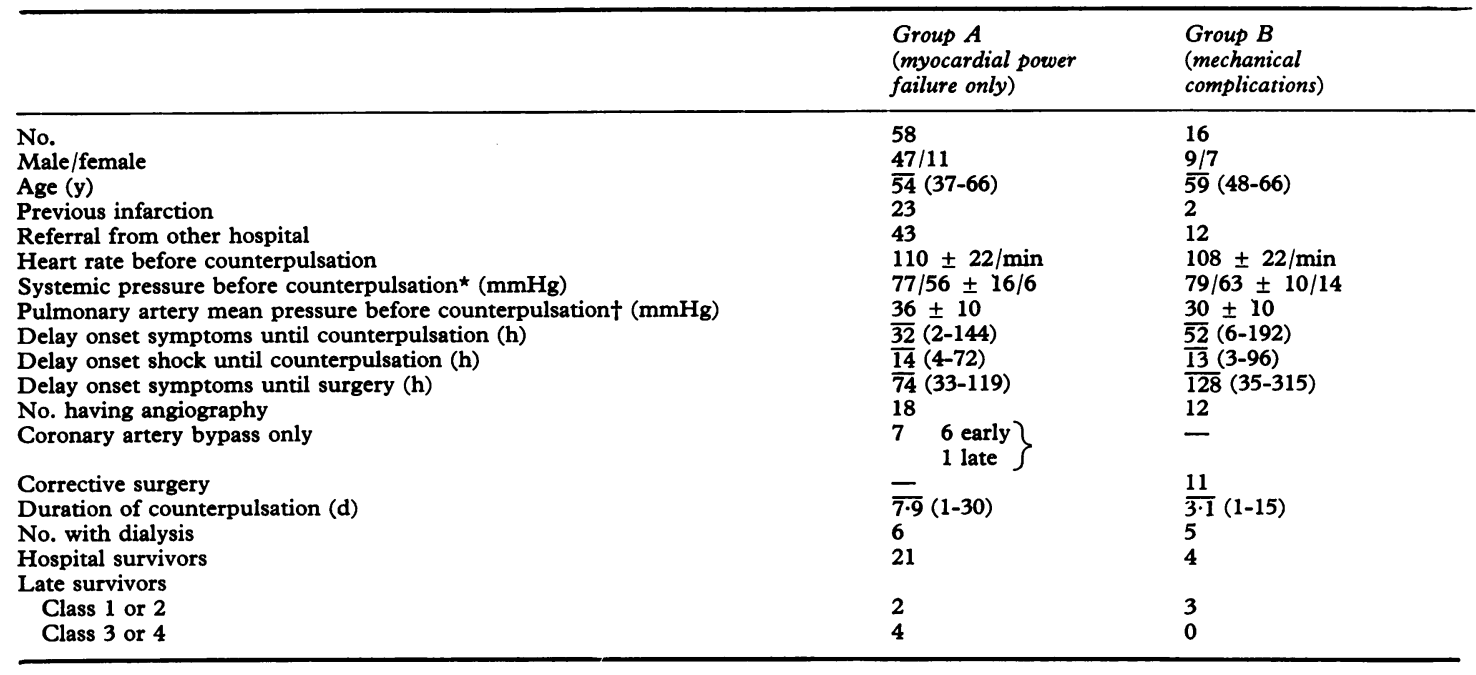

^Excluding 7 patients whose systemic pressure was unrecordable. tMeasured in 32 patients.

Table 2 Patients without shock

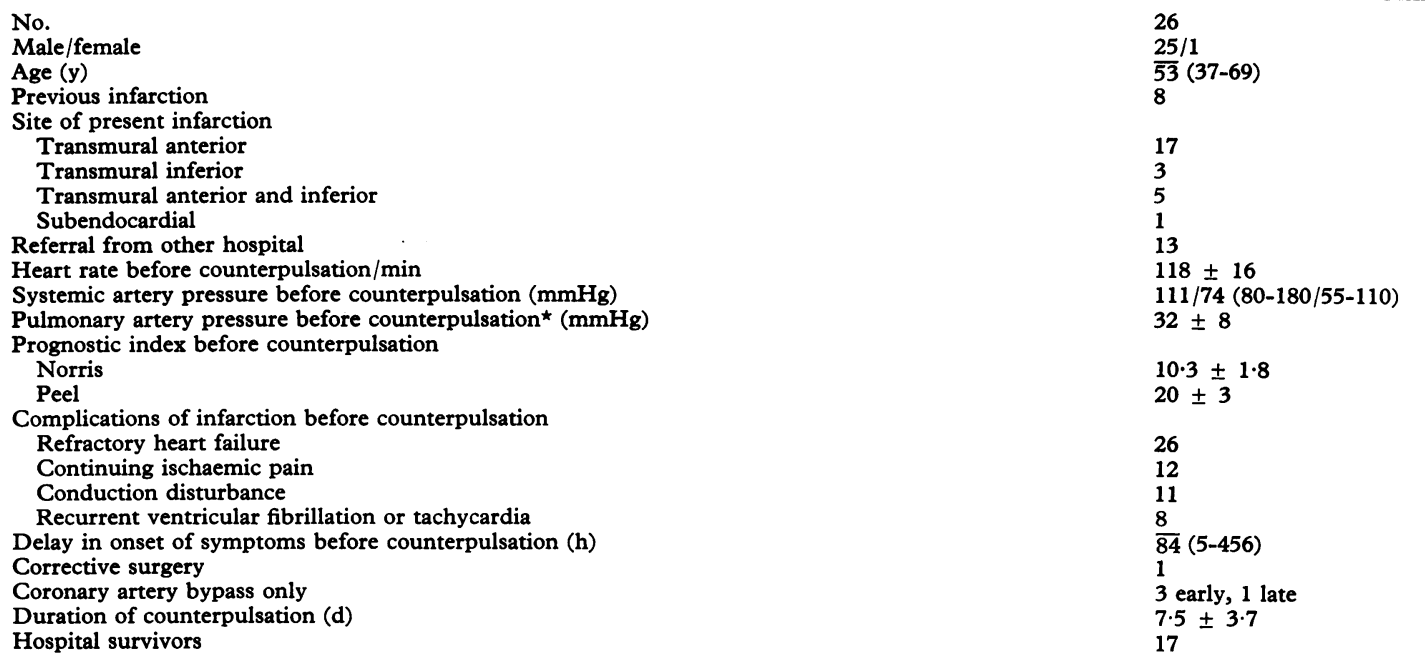

$\star$ Measured in 18 patients.

Of the 74 patients in shock, 33 died during counterpulsation and another 16 died later in hospital. Of the 49 hospital deaths, 47 were attributable to heart failure (with acute renal failure also present in 32). Two deaths resulted from cardiac tamponade from undiagnosed heart rupture. Mortality rate was highest on the first day of counterpulsation and decreased progressively thereafter 
Table 3 Mechanical complications causing shock

Septal rupture only

Subacute heart rupture with tamponade

Septal rupture with subacute heart rupture

Papillary muscle rupture

Ventricular aneurysm

Haemorrhagic pericarditis with tamponade

\begin{tabular}{ll}
\hline Total & 16
\end{tabular}

(Fig. 1); there was no indication from these mortality figures of secondary deterioration after the first 24 hours of counterpulsation.

Of the 74 patients, 29 underwent cardioangiography during the period of circulatory assistance; 18 underwent cardiac surgery as a consequence. Six had early aortocoronary bypass surgery only, while 11 had correction of a mechanical defect with or without coronary bypass as well (Table 1). Corrective procedures were: closure of septal defect (6), mitral valve replacement (2), excision of aneurysm (1), infarctectomy with pericardial drainage (1), and pericardial drainage alone (1).

Early coronary artery bypass graft surgery did not confer any benefit. Of the 6 patients so treated, 4 died in hospital. Correction of a mechanical defect on the other hand often had dramatic consequences. The 2 patients with haemopericardium treated by open drainage improved greatly though 1 who remained in shock required a further period of counterpulsation after operation before satisfactory renal function returned. Both left hospital in good condition as did the patient whose aneurysm was excised. Neither patient with ruptured papillary muscle and only one with septal defect left hospital; this patient, however, made a complete recovery. The experience with ruptured septum and papillary muscle was disappointing, with only 1 survivor in 10 treated. This may have been because of the late

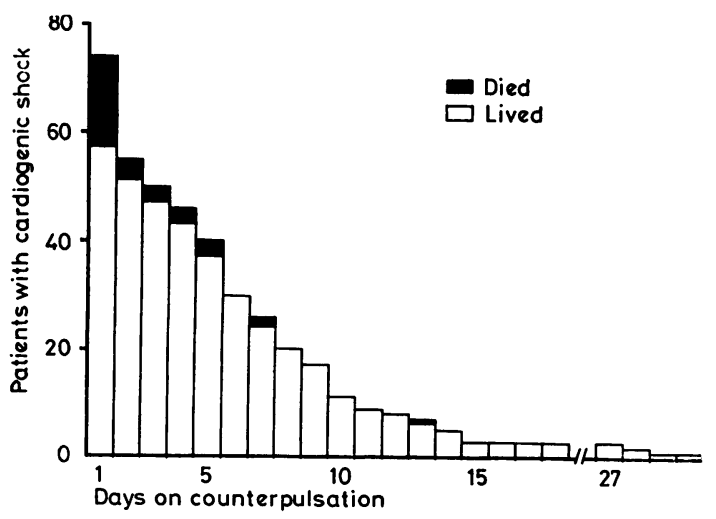

Fig. 1 Daily mortality during counterpulsation fo:

patients in cardiogenic shock. intervention with surgical repair performed 20 to 220 (mean 65) hours after the onset of shock and 8 to 216 (mean 48) hours after initiation of counterpulsation. The mitral valve repair remained intact in both cases undergoing valve replacement, but in 3 of the 6 patients undergoing repair of septal defect (including the survivor) the repair subsequently broke down. The survivor had a further patch inserted 12 weeks after the first operation.

Twenty-five patients left hospital-21 who had no mechanical defect and 4 who did. Sixteen patients died in the follow up period-14 from severe heart failure, 1 from reinfarction, and 1 from cancer. Both patients who underwent early coronary artery bypass grafting alone died in the follow up period. Long-term results were poor (Fig. 2), with only 10 per cent survival at 4 years. Long-term results were dismal in patients without mechanical complications, whose survival rate was 6 per cent at 4 years (there being only 6 of 58 alive at the time of follow up) (Fig. 3). Results were better in patients who underwent correction of a mechanical defect with only 1 late death (from cancer) in 4 hospital survivors. Survivor status was also better in the patients with corrected mechanical defects, all having returned to work or previous activities and all being in New York Heart Association functional class 1 or 2 . In contrast, only 2 of the 6 living patients who had no mechanical complication were in functional class 1 or 2 .

Late survival and survivor status was related to the delay in initiating counterpulsation after the

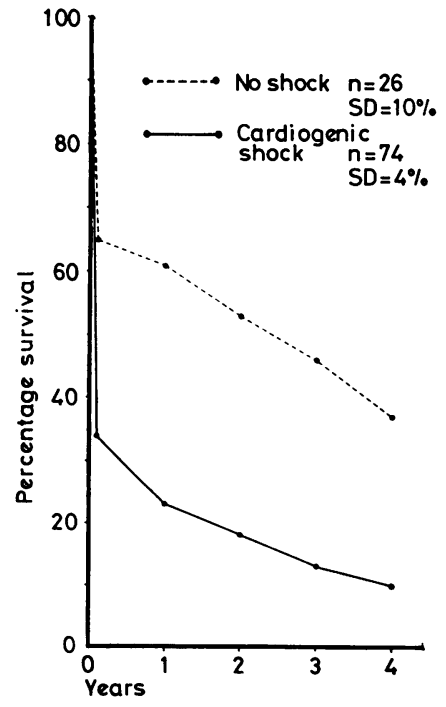

Fig. 2 Life tables, all patients. 


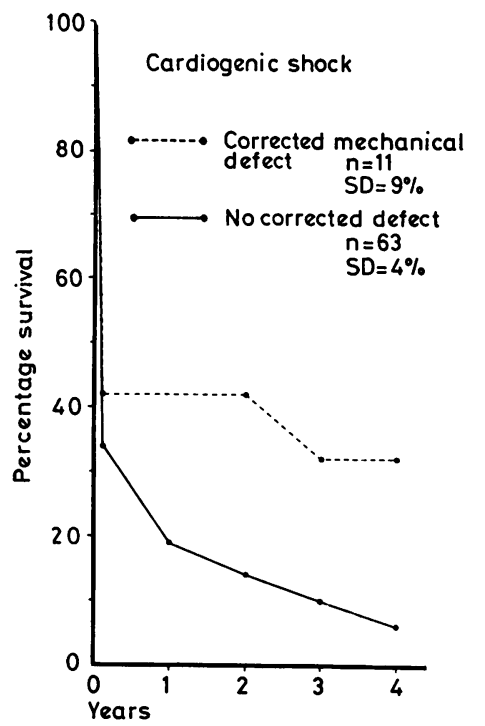

Fig. 3 Life tables, 74 patients in cardiogenic shock with and without corrected mechanical defects.

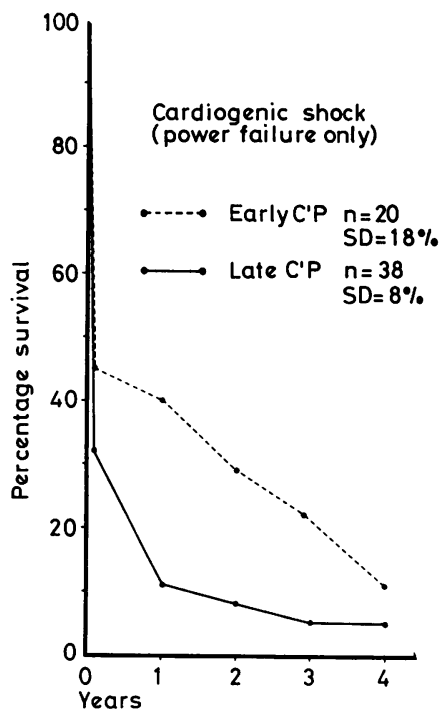

Fig. 4 Life tables, 58 patients in cardiogenic shock without mechanical defects. Early counterpulsation (CP) which started within 8 hours of the apparent onset of shock; late counterpulsation which started 8 hours after apparent onset of shock.

onset of shock. For patients without mechanical complications, late survival at 1 to 4 years was almost twice as high in patients undergoing counterpulsation within 8 hours of the apparent onset of shock as compared with those so managed more than 8 hours after the onset of shock (Fig. 4). Both late survivors in functional class 1 or 2 had undergone counterpulsation within 8 hours of the onset of shock, while all 4 late survivors in functional class 3 or 4 had undergone counterpulsation more than 8 hours after onset of shock.

(b) PATIENTS WITHOUT SHOCK (Table 2)

All these patients had severe left ventricular failure, refractory to medical therapy. This was the indication for counterpulsation. All had at least one other complication of infarction in addition-recurrent ischaemic pain (12), conduction disturbances (11), recurrent ventricular fibrillation or tachycardia (8).

All patients showed improvement with initiation of counterpulsation. The most dramatic effect was on ischaemic heart pain which was present in 12 patients; pain was abolished within minutes in 11 patients and within 12 hours in the other. Symptomatic improvement from left ventricular failure was usually manifest within 2 hours, with radiological clearing of pulmonary oedema usually occurring by the third day of counterpulsation. Pulmonary artery pressure fell from $32 \pm 8 \mathrm{mmHg}$ before counterpulsation to $19 \pm 6 \mathrm{mmHg}(\mathrm{P}<0.001)$ by the end of the first day, and heart rate from $118 \pm 16$ beats/minute to $104 \pm 17$ beats/minute $(P<0.001)$ by the end of the first day. Eleven patients had conduction disturbances before counterpulsation; normal conduction was established within 48 hours in 8.

Recurrent ventricular arrhythmias became less frequent with initiation of counterpulsation in the 8 patients so affected. Counterpulsation was continued for 1 to 15 (mean 7.9) days. When counterpulsation was stopped there was little alteration in heart rate or in pulmonary or systemic pressure in the whole group, though in some patients there were signs of deterioration.

Nine patients died in hospital (mortality rate $35 \%$ ). Six deaths were attributable to heart failure and 3 to primary ventricular fibrillation during hospital convalescence. One patient died during the period of counterpulsation and 8 after this had been terminated. Results were poor in patients treated more than 1 week after the onset of infarction; all but one (with pseudoaneurysm) died in hospital of heart failure. Results were good in patients whose heart failure was associated with continuing ischaemic pain; there was only 1 hospital death in 12 such patients. Four patients underwent coronary artery bypass surgery, 3 in the acute stage and 1 6 weeks after termination of counterpulsation. Of the 3 patients undergoing early coronary artery bypass, 2 died in hospital.

Of the 17 hospital survivors, 5 died during the follow up period. Survival at 4 years was 37 per cent 
(Fig. 2). Two late deaths followed reinfarction ( 1 sudden, 1 from acute cardiac failure) while 3 were attributable to chronic heart failure. Eight of the 12 patients alive at follow up were in functional class 1 or 2 while 4 were in class 3 or 4 .

Late results were good in patients with continuing ischaemic pain. There was only 1 late death in this group and 7 of the 10 survivors at follow up were in functional class 1 or 2 . The patient with mechanical complication likewise did well: 5 months after discharge he chased and overpowered a burglar.

\section{(c) CoMplications (Table 4)}

Complications of counterpulsation were usually evident early and usually occurred in poor risk patients. Of the 19 complications, 13 occurred on the first day, 4 subsequently during counterpulsation, and 2 after removal of the balloon catheter (Fig. 5); there were no complications after discharge from hospital. Of the 19 complications, 17 occurred in patients with cardiogenic shock, and only 2 in patients without shock. No patient died as a direct result of any complication.

Signs of impaired perfusion of the leg-pallor, coolness, diminished pulses-were often seen without ischaemia after insertion of the balloon catheter into the femoral artery. Such signs were usually transient. Thrombus was frequently found in the

Table 4 Complications of counterpulsation

\begin{tabular}{lr}
\hline Ischaemia of leg (1 with gangrene) & 10 \\
Arterial dissection & 3 \\
Bleeding (1 with infection) & 3 \\
Balloon damage & 2 \\
Embolism & 1 \\
\hline Total & 19 \\
\hline
\end{tabular}

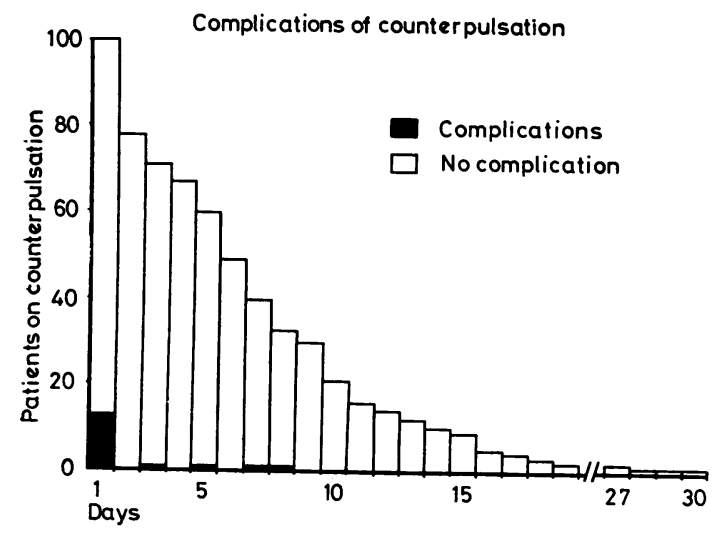

Fig. 5 Onset of counterpulsation complications in all patients. femoral artery after removal of the catheter without any signs of ischaemia having been present before. Thrombus was always sought during the removal procedure, and, when present, removed with Fogarty catheters.

\section{Discussion}

Results presented here suggest a wider role for counterpulsation in acute myocardial infarction than currently held. The improved hospital survival for patients with cardiogenic shock is similar to that reported by others who have attributed results to early coronary bypass surgery (Dunkman et al., 1972; Sanders et al., 1972; Leinbach et al., 1973; Miller et al., 1974; Willerson et al., 1975; Bardet et al., 1977; Erich et al., 1977). Our results were no better in patients undergoing bypass surgery than in those treated with counterpulsation alone. These findings were welcome because we had found early angiographic assessment and surgery a complex undertaking, tiring to the patient, logistically difficult, disruptive of routine work, and demoralising to staff when unsuccessful. The findings were not unexpected because we could not understand how bypass surgery performed 48 hours and more after the onset of symptoms could influence the progression of ischaemia to infarction-a process which in most cases appears to be complete within the first 24 to 48 hours of the onset of symptoms (Sobel et al., 1972; Braunwald, 1974; Norris et al., 1975). Proponents of early surgical revascularisation have cited 'balloon dependence' (Dunkman et al., 1972; Sanders et al., 1972) and secondary deterioration on counterpulsation (Dilley et al., 1973; Erich et al., 1977) as reasons for not persevering with counterpulsation alone. We found that patients who were 'balloon dependent' at 1 or 2 days were usually not so at 7 or 14 days. We have rarely seen secondary deterioration during counterpulsation, the usual finding (reflected in haemodynamic patterns and mortality rates (Fig. 1)) being continued improvement with the passage of time. Where reported (Dilley et al., 1973; Erich et al., 1977), secondary deterioration may have been the result of angiographic investigation and trials of weaning. We attributed the gradual improvement with time to gradual recovery of reversibly damaged myocardium (Heyndrickx et al., 1975) and development of collaterals.

Gradual improvement in cardiac performance over several days after infarction has been documented (Russell et al., 1970). It is interesting that the average duration of counterpulsation in this series ( 7.0 days) was similar to the average duration of vasodilator therapy chosen by Chatterjee 
et al. (1976) (7.6 days) on the basis of stabilisation of haemodynamics and clinical improvement.

Despite the improved early results in patients with cardiogenic shock caused by myocardial power failure the general outlook is still poor with high morbidity and mortality in the ensuing years from chronic cardiac failure. These results have been obtained however in a group of patients who underwent counterpulsation more than 24 hours on average after the onset of symptoms when signs of massive irreparable myocardial damage were already apparent. Results were far better in patients treated early. It is probably unrealistic to expect better results in patients treated as late as those described here.

Results in patients with mechanical defects were similar to those reported elsewhere (Sanders et al., 1972; Leinbach et al., 1973; Bardet et al., 1977). We believe that results would have been even better still had we proceeded expeditiously to counterpulsation, angiography, and surgical correction. Five patients in this series had subacute rupture of the heart (O'Rourke, 1973) with haemopericardium; in 2 cases this was associated with septal rupture. After septal rupture, subacute heart rupture was the most common mechanical complication encountered. Surprisingly there is no mention of this complication in other published series except as a cause of death in patients treated with cardiogenic shock (Kantrowitz et al., 1969; Bardet et al., 1977). Subacute heart rupture proved difficult to diagnose (and was missed completely in 2 patients even at diagnostic angiography), but we believe it should be strongly suspected in patients with late onset of cardiogenic shock (more than 24 hours after onset of symptoms), especially when signs of right heart failure are dominant (O'Rourke, 1973) even in the absence of classical features of tamponade. Our present procedure is to proceed promptly to cardiac surgery in patients with echocardiographic and clinical evidence of tamponade.

Use of counterpulsation in patients with refractory heart failure but without shock was a logical extension of our experience in cardiogenic shock and represented an attempt to prevent shock. After patients with cardiogenic shock, this group has the highest mortality of any occurring after infarction. Surprisingly, only 2 similar series have been reported before (Willerson et al., 1975; Hagemeijer et al., 1977). In the absence of controls it is not possible to be sure how these patients would have fared without counterpulsation. An attempt was made to estimate hospital survival from prognostic indices of Peel et al. (1962) and Norris et al. (1969). In using these indices it must be conceded that they were developed before the advent of coronary care wards and may overestimate mortality. Against this however coronary care has not led to improved survival in patients with severe heart failure (Meltzer and Kitchell, 1972), and, further, the indices were applied by us to patients after conventional treatment had failed rather than before any treatment had been started. It is, therefore, probable that mortality was reduced by counterpulsation.

As in patients with cardiogenic shock, patients without shock did not benefit from early coronary artery bypass surgery. In addition, results were poor in patients undergoing counterpulsation late after the onset of symptoms (unless a mechanical defect was present) and good in patients treated early especially if there was evidence of continuing ischaemia. These findings are easily explicable on the basis of counterpulsation causing relief of myocardial ischaemia and reduction in infarct size (Mueller et al., 1971; Braunwald, 1974).

After surgical revascularisation, counterpulsation is probably the most powerful method currently known for relieving myocardial ischaemia (Mueller et al., 1971; Braunwald, 1974). Logic dictates that it must have a role in the early stage of acute myocardial infarction. Despite its sound physiological basis and impressive results under experimental circumstances, counterpulsation has been restricted in the main to patients with shock and massive established infarction in whom all conventional treatment has failed. Certainly infarction can spread further in a shocked patient (Page et al., 1971) but it makes little sense to aim at redressing only the secondary effects of shock. The approach to counterpulsation in patients with infarction has been ultraconservative as though the procedure itself carries little chance of benefit and great risk of harm. Chance of benefit indeed appears to be great (provided counterpulsation is initiated early) and the risk of complication quite low. In our hands complications have been infrequent and have posed little risk of life and limb. Contrary to other views (Pace et al., 1976) we believe that the complications are largely those of the insertion procedure in a desperately ill patient. Once counterpulsation is established and the patient responding, the chance of late complication is remote and very low indeed when judged against the chance of clinical improvement. Risk of late complications we believe should not dictate early termination of counterpulsation within 1 to 2 weeks in a patient who is responding weil.

There has been increasing use of counterpulsation in coronary insufficiency or threatening infarction (Mundth, 1976). That counterpulsation has established a role in this low risk condition testifies to the safety of the procedure itself. 
We have sought no experience in this area, being currently satisfied with conventional treatment: over the past 5 years we have had 7.9 per cent infarction rate with $5 \cdot 1$ per cent mortality rate in 79 patients with coronary insufficiency, refractory to medical therapy, who underwent aortocoronary bypass surgery. Happy as we are with the relative safety of counterpulsation in poor risk patients, we have reservations about the risk against possible benefit in patients with coronary insufficiency.

To date clinical experience with counterpulsation in myocardial infarction has been confined almost exclusively to 2 extremes of the clinical spectrumfrom threatening infarction on the one hand to cardiogenic shock on the other: from a condition with around 5 per cent mortality risk on conventional treatment on the one hand to 95 per cent on the other. Evidence of clinical benefit in the two groups of patients suggests a role throughout the spectrum. The data presented in this paper support such a concept: that counterpulsation may have an important place by itself in treatment of acute infarction, provided intervention is prompt. We are currently investigating this with a randomised controlled trial.

We acknowledge with thanks the efforts of the hospital's nursing staff and the contribution of our medical colleagues within and without the hospital. The project was supported by grants from the Ramaciotti Foundation, the National Health and Medical Research Council, and the National Heart Foundation of Australia.

\section{References}

Bardet, J., Masquet, C., Kahn, J. C., Gourgon, R., Bourdarias, J. P., Mathivat, A., and Bouvrain, Y. (1977). Clinical and hemodynamic results of intra-aortic balloon counterpulsation and surgery for cardiogenic shock. American Heart fournal, 93, 280-288.

Berne, R. M. (1964). Regulation of coronary blood flow. Physiological Reviews, 44, 1-29.

Braunwald, E. (1974). Reduction of myocardial infarct size. New England fournal of Medicine, 291, 525-526.

Brown, B. G., Goldfarb, D., Topaz, S. R., and Gott, N. L. (1967). Diastolic augmentation by intra-aortic balloon. fournal of Thoracic and Cardiovascular Surgery, 53, 789-804.

Chatterjee, K., Swan, H. J. C., Kaushik, V. S., Jobin, G., Magnusson, P., and Forrester, J. S. (1976). Effects of vasodilator therapy for severe pump failure in acute myocardial infarction on short-term and late prognosis. Circulation, 53, 797-802.

Dilley, R. B., Ross, J., Jr., and Bernstein, E. F. (1973). Serial hemodynamics during intra-aortic balloon counterpulsation for cardiogenic shock. Circulation, 47 and 48, Suppl. III, 99-104.

Dunkman, W. B., Leinbach, R. C., Buckley, M. J., Mundth, E. D., Kantrowitz, A. R., Austen, W. C., and Sanders, C. (1972). Clinical and hemodynamic results of intra-aortic balloon pumping and surgery for cardiogenic shock.
Circulation, 46, 465-477.

Erich, D. A., Biddle, T. L., Kronenberg, M. W., and Yu, P. N. (1977). The hemodynamic response to intra-aortic balloon counterpulsation in patients with cardiogenic shock complicating acute myocardial infarction. American Heart fournal, 93, 274-279.

Forrester, J. S., Diamond, G., Chatterjee, K., and Swan, H. J. C. (1976). Medical therapy of acute myocardial infarction by application of hemodynamic subsets. Part II. New England fournal of Medicine, 295, 1404-1413.

Goldfarb, D., Brown, B. G., Conti, C. R., and Gott, V. L. (1968). Cardiovascular responses to diastolic augmentation in the intact canine circulation and after ligation of the anterior descending coronary artery. Fournal of Thoracic and Cardiovascular Surgery, 55, 243-254.

Hagemeijer, F., Laird, J. D., Haalebos, M. M., and Hugenholtz, P. G. (1977). Effectiveness of intra-aortic balloon pumping without cardiac surgery for patients with severe heart failure secondary to a recent myocardial infarction. American fournal of Cardiology, 40, 951-956.

Heyndrickx, G. R., Millard, R. W., McRitchie, R. J., Maroko, P. R., and Vatner, S. F. (1975). Regional myocardial function and electrophysiological alterations after brief coronary artery occlusion in conscious dogs. Fournal of Clinical Investigation, 56, 978-985.

Kantrowitz, A., Krakauer, J. S., Rosenbaum, A., Butner, A. N., Freed, P. S., and Jaron, D. (1969). Phase shift balloon pumping in medically refractory cardiogenic shock: results in 27 patients. Archives of Surgery, 99, 739-743.

Kantrowitz, A., Phillips, S. J., Butner, A. N., Tjønneland, S., and Haller, J. D. (1968). Technique of femoral artery cannulation for phase shift balloon pumping. Fournal of Thoracic and Cardiovascular Surgery, 56, 219-220.

Leinbach, R. C., Gold, H. K., Dinsmore, R. E., Mundth, E. D., Buckley, M. J., Austen, W. G., and Sanders, C. A. (1973). The role of angiography in cardiogenic shock. Circulation, 47 and 48, Suppl. III, 95-98.

Maroko, P. R., Bernstein, E. F., Libby, P., DeLaria, G. A., Covell, J. W., Ross, J., Jr., and Braunwald, E. (1972). Effects of intra-aortic balloon counterpulsation on the severity of myocardial ischaemic injury following acute coronary occlusion. Circulation, 45, 1150-1159.

Meltzer, L. E., and Kitchell, J. R. (1972). The development and current status of coronary care. In Textbook of Coronary Care, p. 3, ed L. E. Meltzer and A. J. Dunning. Excerpta Medica, Amsterdam.

Miller, M. G., Hedley-Whyte, J., Weintraub, R. M., Restall, D. S., and Alexander, M. (1974). Surgery for cardiogenic shock. Lancet, 2, 1342-1345.

Mueller, H., Ayres, S. M., Conklin, E. F., Gianelli, S., Jr., Mazzara, J. T., Brace, W. T., and Nealon, T. F., Ir. (1971). The effects of intra-aortic counterpulsation on cardiac performance and metabolism in shock associated with acute myocardial infarction. Fournal of Clinical Investigation, 50, 1885-1900.

Mundth, E. D. (1976). Mechanical and surgical interventions for the reduction of myocardial ischaemia. Circulation, $\mathbf{5 3}$ and 54, Suppl. 1, 176-185.

Norris, R. M., Brandt, P. W. T., Caughey, D. E., Lee, A. J., and Scott, P. J. (1969). A new coronary prognostic index. Lancet, 1, 274-278.

Norris, R. M., Whitlock, R. M. L., Barratt-Boyes, C., and Small, C. W. (1975). Clinical measurement of myocardial infarct size: modification of a method for the estimation of total creatine phosphokinase release after myocardial infarction. Circulation, 51, 614-620.

O'Rourke, M. F. (1973). Subacute heart rupture following myocardial infarction: clinical features of a correctable condition Lancet, 2, 124-126. 
O'Rourke, M. F. (1977). Arterial counterpulsation in the management of ischaemic heart disease. Australian and New Zealand Fournal of Surgery, 47, 21-26.

O'Rourke, M. F., Chang, V. P., Windsor, H. M., Shanahan, M. X., Hickie, J. B., Morgan, J. I., Gunning, J. F., Seldon, R. W., Hall, G. V., Michell, G., Goldfarb, D., and Harrison, D. G. (1975). Acute severe cardiac failure complicating myocardial infarction: experience with 100 patients referred for consideration of mechanical left ventricular assistance. British Heart fournal, 37, 169-181.

O'Rourke, M. F., Walsh, B., Fletcher, M., and Crowley, A. (1976). Impact of the new generation coronary care unit. British Medical fournal, 2, 837-839.

Pace, P., Tilney, N., Couch, N., and Lesch, M. (1976). Peripheral arterial complications of intra-aortic balloon counterpulsation (abstract). Circulation, 53 and 54, Suppl. II, 13.

Page, D. L., Caulfield, J. B., Kastor, J. A., DeSanctis, R. W. and Sanders, C. A. (1971). Myocardial changes associated with cardiogenic shock. New England fournal of Medicine, 285, 133-137.

Peel, A. A. F., Semple, T., Wang, I., Lancaster, W. M., and Dall, J. L. G. (1962). A coronary prognostic index for grading the severity of infarction. British Heart fournal, 24, 745-760.

Powell, W. J., Jr., Daggett, W. M., Magro, A. E., Bianco, J., Buckley, M. J., Sanders, C. A., Kantrowitz, A. R., and Austen, W. G. (1970). Effects of intra-aortic balloon counterpulsation on cardiac performance, oxygen consumption and coronary blood flow in dogs. Circulation Research, 26, 753-764.

Russell, R. O., Jr., Rackley, C. E., Pombo, J., Hunt, D., Potanin, C., and Dodge, H. T. (1970). Effects of increasing left ventricular filling pressure patients with acute myocardial infarction. Fournal of Clinical Investigation, 49, 1539-1550.

Sianders, C. A., Buckley, M. I., Leinbach, R. D., Mundth, E. D., and Austen, W. G. (1972). Mechanical circulatory assistance: current status and experience with combining circulatory assistance, emergency coronary angiography and acute myocardial revascularisation. Circulation, 45, 12921313.

Sarnoff, S. J., Braunwald, E., Welch, C. H., Jr., Case, R. B., Stainsby, W. N., and Macruz, R. (1958). Hemodynamic determinations of oxygen consumption of the heart with special reference to the tension-time index. American fournal of Physiology, 192, 148-156.

Scheidt, S., Wilner, G., Mueller, H., Summers, D., Lesch, M., Wolff, G., Krakauer, J., Rubenfire, M., Fleming, P., Noon, G., Oldham, N., Killip, T., and Kantrowitz, A. (1973). Intra-aortic balloon counterpulsation in cardiogenic shock: report of a co-operative clinical trial. New England fournal of Medicine, 288, 979-984.

Sobel, B. E., Bresnahan, G. F., Shell, W. E., and Yoder, R. D. (1972). Estimation of infarct size in man and its relation to prognosis. Circulation, 46, 640-648.

Soroff, H. S., Levine, J. H., Sachs, B. F., Firtwell, W. C., and Deterling, R. A. (1963). Assisted circulation. II. Effects of counterpulsation on left ventricular oxygen consumption and hemodynamics. Circulation, 27, 722-731.

Wan, S. H., Thompson, P. L., Dowling, J. T., and Sloman, G. (1971). Cardiogenic shock: a review of one year's experience. Medical fournal of Australia, 1, 1000-1004.

Willerson, J. T., Curry, G. C., Watson, J. T., Leshin, S. J. Ecker, R. R., Mullins, C. B., Platt, M. R., and Sugg, W. L. (1975). Intra-aortic balloon counterpulsation in patients in cardiogenic shock, medically refractory left ventricular failure and/or recurrent ventricular tachycardia. American Fournal of Medicine, 58, 183-191.

World Health Organization. Regional Office for Europe (1970). Ischaemic Heart Disease Registers EURO 5010 (4), p. 25. The Organization, Copenhagen.

Requests for reprints to Dr Michael F. O'Rourke, Medical Professorial Unit, St Vincent's Hospital, Darlinghurst, New South Wales 2010, Australia. 